\title{
The Role of Cultural Promotion As an Integral Component of Leipzig's Urban Development
}

\author{
Jean-Claude Garcia-Zamor \\ Public Administration, Florida International University, University Park, USA \\ Email: garciazamor@hotmail.com
}

Received May 23 $3^{\text {rd }}$, 2013; revised July $1^{\text {st }}$, 2013; accepted July $15^{\text {th }}$, 2013

\begin{abstract}
Copyright (c) 2013 Jean-Claude Garcia-Zamor. This is an open access article distributed under the Creative Commons Attribution License, which permits unrestricted use, distribution, and reproduction in any medium, provided the original work is properly cited.
\end{abstract}

\begin{abstract}
After the reunification in 1990, Leipzig — as well as other East German cities - had to face the challenges of the new political-administrative system and an open global economy. Through the systematic implementation of its evolving urban development strategies, the city has developed positively in many areas. After the German reunification, most of Leipzig's districts lacked cultural leisure services that would have been fit for all age groups and close to their homes. In the early 1990s, the establishment of such urgently needed socio-cultural centers was initiated on the one hand by official authorities and on the other by the citizens themselves. Many newly founded associations and initiatives strove hard to maintain the existing or to develop new cultural activities. In order to implement the latter, they were not only interested in the already established cultural sites, but particularly in former industrial structures or other buildings with a rich historical background. The best project in this effort is the world-famous Spinnerei. These urban environments offered vast opportunities for artists, the independent scene, cultural workers and creative industries alike. A large number of Leipzig's cultural institutions originated from civic engagement and were then, in times of economic recovery, incorporated into municipal ownership. Nowadays, they are threatened to be re-privatized as the city's means of cultural funding are gradually reaching their limits. But Leipzig planning officials still think that the promotion of cultural projects in the neighborhoods provides a climate where culture is respectfully seen as a precious opportunity for urban development. Through an extensive and varied offer of cultural activities, otherwise marginalized citizens can be integrated in social life and participate in democratic processes.
\end{abstract}

Keywords: Integrated Planning; SEKo 2020; Cultural Promotion

\section{Urban Development since 2000: Upward Trend after the Paradigm Shift}

At the beginning of the 20th century, Leipzig was one of the four largest cities in Germany with a prosperous and diverse economic structure. Due to the centralized system and the international isolation of the former GDR, the city's population and importance decreased. After the reunification in 1990, Leipzig - as well as other East German cities_had to face the challenges of the new political-administrative system and an open global economy. In comparison to other East German cities, Leipzig has very early recognized ways of acquiring fundings from higher administrative levels. Additionally, thanks to the local municipality reform of $1999 / 2000$, the limit of 500,000 inhabitants was reached, so that the city was eligible to higher sums of subsidies. Together with the resulting increased tax revenues, this promoted a sustainable urban development. Through the systematic implementation of its evolving urban development strategies, the city has developed positively in many areas. Nowadays, the Saxon metropolis is a center of economic, social and cultural life. Because of massive tax incentives, "global players" like BMW, Porsche, DHL and Amazon settled in Leipzig in the early 2000s. An essential basis for this positive trend of the recent years was Leipzig's sophisticated infrastructural system. In 2003, the "City Tunnel” as the most important transportation project of the coming years was initiated.

The newly designed public spaces and the broad range of educational, recreational and sports facilities have helped to improve living conditions in the city. The overall appearance of Leipzig has drastically improved due to various developments such as the reduced environmental pollution, the renovation of entire streets and the flooding of the former mining areas. Furthermore, other factors such as culture and education are contributing to the quality of life in the city. Cultural diversity is an important pillar of Leipzig as a "city of citizens". Subcultural phenomena and institutionally funded cultural activities have multiplied recently. The functional concept of culture is closely linked to those of economy, education and social affairs. Since all of these sectors are strongly interdependent, it seems only consequential to organize and plan them in an integrative manner. Therefore, a paradigm shift in Leipzig's urban development planning strategies could be observed around the turn of the millennium. Until then, it used to strictly separate the different departments and focused on isolated projects one at a time. The excess capacities caused by shrinkage processes - vacant properties, underutilized infrastructures and unoccupied buildings of various kinds - can only be used for urban development processes through integrated planning. That is why today, depart- 
ments like economics, infrastructure or cultural development are viewed in their common context. The different institutions and players that are involved in urban development planning processes have to communicate and to cooperate.

This integrated planning approach as it is manifested in the Leipziger Stadtentwicklungskonzept 2020 (SEKo 2020) will be discussed in the next section. Then cultural promotion will be described as a possible way of developing urban areas. Furthermore, the development of Leipzig's cultural scene over the past 20 years will be outlined. What role does "culture", or more precisely "social culture", play in the thematic framework of urban development? To what extent could it be "used" for the latter and how can it be funded in practice? To pursue these questions, my research assistant interviewed the district manager of Leipziger Westen, Mrs. Peggy Diebler, who described the implementation practices that were implemented in the districts of Lindenau and Plagwitz.

\section{Leipzig's Urban Development Plan "SEKo 2020" as an Integrative Approach}

Cross-linking different sectors, "SEKo 2020" provides a binding framework that serves as a guideline for the development of the city in the years to come. It is the basis for budget planning and sets priorities for the future use of municipal funds and grants by designating main topics and priority areas of action. A key package of measures and specific implementation options was developed to reach the objectives defined by SEKo 2020. The concept is a basis for goal-oriented crossdepartmental actions not only within the local urban development authorities, but also for the cooperation with various stakeholders outside the municipal administration. That kind of inclusiveness is a required condition for any project applying for funding to the Free State of Saxony. Another cross-departmental funding option is the European Regional Development Fund (ERDF). In contrast, other programs like the federally funded Stadtumbau Ost (urban restructuring in East Germany) are rather project-oriented. They are neither limited to certain areas, nor do they require the cooperation of the applicants and local actors. To be financed from federal or other funding pots, projects must above all fulfill the requirement of sustainability.

Extensive discussions during the preparation of SEKo have created new structures of communication and coordination within the Leipzig city council. These need to be maintained and even intensified in order to ensure an efficient implementation of SEKo. Among other things, this concerns the cooperation with municipal subsidiaries, in particular the housing and construction company in Leipzig (Leipziger Wohnungs-und Baugesellschaft, LWB), the municipal waterworks (Kommunale Wasserwerke Leipzig, KWL) and the energy supplier "Stadtwerke Leipzig" (SWL). Just as important is the interaction with non-administrative players such as clubs, individuals or local businesses.

The integrated urban development plan SEKo 2020 will eventually be successful. Even if the objectives set for 2020 cannot be entirely reached by then, it is planned to further pursue the concept. With regularly scheduled monitoring and evaluation, it will continue to evolve.

\section{Cultural Promotion as a Component of Urban Development}

After the German reunification, most of Leipzig's districts lacked cultural leisure services that would have been fit for all age groups and close to their homes. In the early 1990s, the establishment of such urgently needed socio-cultural centers was initiated on the one hand by official authorities (the municipality and the Kulturamt) and on the other by the citizens themselves. Six initially municipal buildings are now independently operated. The city has not only subsidized this transformation but is also responsible for the structural maintenance of the houses. By the mid-90s, several socio-cultural centers were privatized, but only a few of them retained their function as cultural sites. Many newly founded associations and initiatives strove hard to maintain the existing or to develop new (albeit sometimes only temporary) cultural activities. In order to implement the latter, they were not only interested in the already established cultural sites, but particularly in former industrial structures or other buildings with a rich historical background. These urban environments offered vast opportunities for artists, the independent scene, cultural workers and creative industries alike. In that way, several districts-primarily Plagwitz and Neulindenau - have developed a characteristic neighborhood culture which is not at all defined by institutions of the so called high culture (although they consume a large portion of the city's cultural budget). Instead, independent subcultural phenomena are constitutive elements. By now, the largest and best known of these probably is the "Baumwollspinnerei" complex at the western extremity of Karl-Heine-Straße.

Socio-cultural facilities like the "Mühlstraße e.V." in Leipzig's east are important focal points and drivers of cultural and social life in the district. They boost active citizenship and play an important role in the process of integration of marginalized population groups into the social fabric. Certain negative effects of demographic change (such as loneliness in old age, to name just one example) can be mitigated through them. The municipal funding of socio-culture has to start, where both deficits in the existing supply structure and potentials for future development can be observed. If urgently needed, new facilities with additional services can of course be created. Cultural promotion, however, is primarily designed to stabilize the networks that are already in place. Hence, Leipzig's culture is shaped by the successful coexistence of private creative businesses as well as public institutions and the publicly funded independent scene- the latter certainly suffering less from the pressure of being economically efficient. That freedom gives them the opportunity — but also the obligation- to work on an elevated artistic level and to be highly innovative and experimental at the same time. Nevertheless, socio-culture must-just like the private sector-take into account the financial situation of their respective target group. As a result of declining net incomes in certain districts, as well as an increasing proportion of mini- and midi-jobbers or recipients of welfare benefits, it is necessary to adapt concepts and projects in order to meet the changed demands of the stakeholders and to actively prevent a loss in revenues.

A large number of Leipzig's cultural institutions originated from civic engagement and were then, in times of economic recovery, incorporated into municipal ownership. Nowadays, they are threatened to be re-privatized as the city's means of cultural funding are gradually reach their limits. Given the current economic situation, the preservation of cultural networks is far from being granted. It should be remembered, that Leipzig's diverse cultural landscape functions as a decisive advantage for the city in a way that cultural funding is also an important in- 
vestment in the development of the local economy.

\section{Socio-Cultural Promotion and the Rise of the Creative Economy in Leipzig's Current Urban Development Concept "SEKo 2020"}

The city of Leipzig derives its basic objectives of cultural promotion from the cultural development plan of the years 2008 to 2015. Urban cultural institutions continuously aim to expand their offers for people of all ages and to develop new ideas targeted to specific groups. Through increased networking and cooperation among themselves as well as with third parties, Leipzig's cultural institutions seek to use their potentials in a more efficient way in order to reinforce the city's regional, national and international impact. Due to urban demographic changes, socio-spatial differentiations will be necessary in addition to the spatial focuses SEKo 2020 calls for. Educating the social and cultural skills of the population is a possible way of countering the downward spiral in which some districts are stuck. The overall aims are to strengthen socio-culture as a "resonating space" for the formation of public opinion and to contribute to lifelong learning. For this purpose, socially inclusive, inter-generational and multicultural approaches are pursued. Their potentials range from the development of new forms of communication to the implementation of model projects and the establishment of efficient networks. Moreover, socio-culture may very well provide impulses for the artistic cultural scene. Creative industries grow best in cities which, like Leipzig, emanate an omnipresent historical aura and have countless unique features. A generally culture-positive atmosphere, an adequate supply of reasonably priced premises and a sufficient number of cultural institutions and events are vital conditions for a prospering socio-culture and successful creative industries. As these preserve and even help creating new jobs-which represents a major goal of the general SEKo 2020 policy-they support future economic growth and thus ultimately assist urban development.

\section{Implementation Practices-Cultural Promotion from the Perspective of Stakeholders}

To gain insight into the practical implementation of urban development strategies in a cultural context, we asked Mrs. Peggy Diebler about her personal experiences as the district manager of Plagwitz and Lindenau. The interview took place in July 2011 and consisted of five questions that are summarized in the following five sections.

\section{Cultural Promotion and Its Role in the Work of the District Manager of Plagwitz and Lindenau}

The promotion of cultural projects in the neighborhood provides a climate, where culture is respectfully seen as a precious opportunity for urban development. The management of the districts Lindenau and Plagwitz is partly responsible for the distribution of the Verfügunsfonds means. Therefore, they are mainly looking for cooperation partners, such as the "IG Kultur West" and the "Westbesuch e.V.", who explicitly combine culture with urban development. In order to get financial support from the available funds, it is not at all necessary to be a member to one of these clubs, but more importantly to furnish creative ideas.
On multiple levels, arts and culture play into the work of the district management. Mrs. Diebler differentiates three kinds of cultural promotion that are currently being practiced in Leipzig. First, she mentions the municipal funding of the city's existing facilities and institutions. Secondly, she names the subsidization of services that are not in municipal sponsorship. This allocation of money by the department of culture ("Kulturamt") to specific projects is called Fachförderung. In addition to these two funding methods, a third way of cultural promotion enables "unofficial" cultural organizations and initiatives to apply for funds from different programs and funds on a municipal, federal or even European level.

According to Mrs. Diebler, culture is heavily linked to the economy, especially in the field of creative industries, where profit-orientation and a "non-profit attitude" are closely intertwined.

\section{The Public Perception of Cultural Diversity in Plagwitz and Lindenau}

The districts' basic cultural institutions-such as the Musikalische Komödie or the Theater der jungen Welt-are in municipal hands. Well-known cultural sites like the Felsenkeller or the Schaubühne Lindenfels date back to the 1920s and thus represent constitutive elements of the neighborhood's history which always had a vivid culture of entertainment. This is as true today-plenty of people come here especially because of the districts' renowned cultural scene. The public perception of Plagwitz as a "hip art district" is also strongly related to the fact, that the studios of artists with a worldwide reputation (like Neo Rauch, for instance) are located there. Plagwitz and Lindenau are thus a magnet for those who are interested in the fine arts but also for people who intent to express themselves culturally. Since the vacancy rate is still at a fairly high level, the rents are still relatively inexpensive which makes the districts easily accessible even for people with limited financial resources. Moreover, Leipzig West is considered as the cradle of the Wächterhäuser movement that makes decaying houses available to people who are willing (and able) to renovate and maintain these architectural structures. Against a very small fee, these "guardians of the historical buildings" can freely realize their own projects. Additionally, many former industrial sites with large rooms and halls that can easily be adapted to new utilization concepts are still vacant. The Baumwollspinnerei with its large number of studios, event spaces, residences and commercial premises was one of the first cultural pioneers to make use of these potentials. Other important meeting points for the cultural scene and creative industries are the Tapetenwerk, the Westwerk or the Alte Handelsschule in Kleinzschocher. The Karl-Heine-Straße, Zschochersche Straße, Lindenauer Markt or Georg-Schwarz-Straße are actually agglomerations of numerous individual centers of culture. Many of their former retail spaces have been transformed into galleries, bars or various project spaces. Associations like the Westbesuch e.V. with their cultural activities around the Karl-Heine-Straße have had a decisive impact on the development of the neighborhood. People began to rethink the objectives and conditions of sociocultural work: Although cultural initiatives coming from outside the respective districts were openly accepted, serious efforts were made to stimulate the locals' participation in cultural activities. Plenty of occasions such as the Westpaket, the Westbesuch, the Lindenauer Nacht or various other festivals give the 
residents abundant opportunities of creatively working together. This has led to a positive climate of cooperation or at least of peaceful coexistence, even though according to Mrs. Diebler, smaller frictions sometimes are inevitable.

\section{A Short Description of Cultural Promotion in the Districts Supervised by Mrs. Diebler}

Culture is promoted by several different sources that are working entirely independently. For instance, the Kulturstiftung des Freistaates Sachsen is not subsidized by the city of Leipzig. Areas of intensified intervention have been defined by a comprehensive strategy for urban development. The west of Leipzig is considered separately since 1999, when several "lighthouse" sites were promoted in the course of the world fair "Expo 2000”. Subsequently, the European funding program "Urban II" distributed the available means to a greater variety of small projects. Since 2009, Leipzig West is mainly funded by that program. Altogether, these European subsidies positively accelerated the local development of Plagwitz and Lindenau. The various small associations and initiatives were able to professionalize a part of their work. The experiment "Urban II" has impressively shown the benefits of discussing the distribution of funds within a large group of stakeholders. Officials and employees of local businesses as well as civil representatives and members of non-profit organizations participated in the negotiations. This kind of open dialogue is still practiced at present. However, this democratic and integrated approach to cultural funding is still in its infancy. Stakeholders reportedly still tend to strictly separate such fields as music, theater or the fine arts instead of perceiving them as highly interdependent. Mrs. Diebler is optimistic, that all of these facets of cultural life will converge over the course of future debates on urban development.

\section{Difficulties and Possible Improvements in the Work of a District Manager}

It would be desirable that Leipzig generally decides much earlier about the city's annual budget planning. Only in this way, cultural organizations and initiatives can be guaranteed safety for the realization of their projects.

Because numerous official authorities are involved in the organization of cultural events, it would really help to have an expert who could be contacted whenever questions arise in the bureaucratic jungle. This kind of position has already been applied for to the "creative cities" program a long time ago but still hasn't been put into action.

Mrs. Diebler is hoping, that people keep up the good work and hold on to their great enthusiasm, even after the subsidies of the European Regional Development Fund expired.

\section{Mrs. Diebler's View on and Wishes for the Future of Certain Cultural Projects}

When it comes to the development chances of certain areas, Mrs. Diebler attributes prominent long term effects to the recent developments around Lindenauer Markt and Georg-SchwarzStraße, as well as to privately funded projects such as the Baumwollspinnerei, the Tapetenwerk, the Westwerk and the Alte Handelsschule in Kleinzschocher. In these locations, the stakeholders involved in socio-culture and creative industries show a remarkably enthusiastic commitment to their work. Mrs. Die- bler therefore calls them "charitable”, even though the projects in question partly are profit-oriented economic institutions.

Another very big opportunity is located on the Karl-HeineStraße, where as a result of the cooperation between the Schaubühne Lindenfels and the more recently opened LindenfelsWestflügel an important center for the art of puppet theater (Figurentheater) is about to emerge.

If the current negotiations between Deutsche Bahn and the municipal authorities are successful, the city could purchase the very large area around the Plagwitzer Bahnhof and turn it into a park or forest. As a result, even more people, associations or companies will be attracted to the surrounding neighborhoods, because a large open space like this will entice people to use it in multiple different ways. In the first rounds of public hearings, residents, professionals, architects, designers and artists already have enthusiastically attended to the meetings.

For the cultural revival of Leipzig's west in the long term, it is important that people who are actively taking part in certain projects keep on doing so. Till now, most of the protagonists who are working for associations and initiatives are people who are studying or have spare time for other reasons, e.g. because they are stay-at-home parents. When these people enter or reenter their professional career, they will have significantly less time available for their former hobbies. The situation in their respective clubs may then take a drastic turn for the worse, explains Mrs. Diebler. That is why she thinks that the biggest potential lays within projects that are carried out by stakeholders who can connect and harmonize their cultural commitment with their professional career.

\section{Conclusions and Outlook}

A well-functioning cultural promotion may in multiple ways have a positive influence on the development of neighborhoods. It might put a stop to the downward spiral in which several of Leipzig's districts are trapped at the moment. Through an extensive and varied offer of cultural activities, otherwise marginalized citizens can be integrated in social life and participate in democratic processes. Moreover, the livability and the outward image of the neighborhood can be improved. In the near future, cultural funding will probably play an even more important role in the context of urban development. The relatively young concept of integrative plan for urban development will probably be a long work in progress in the course of which municipal authorities and external actors must certainly work together more closely. Old ways of thinking in a closed system must be replaced by open-mindedness. A diverse cultural scene cannot survive without the voluntary work of the citizens.

Hope for the future of Leipzig's independent cultural scene was instilled by a recent decision of the city council. On July 18, 2012 the never implemented policy (dating back to 2008) to allocate five percent of the city's cultural budget to the independent scene was finally activated. Although the level of the original funding is far from being reached today, the subsidies transferred next year will exceed those of 2012 by $600.000 €$ (US\$780,000). In the following two years there ought to be an annual increase of $320.000 €$ (US $\$ 415,000$ ) each year. If this time, the municipal authorities keep their promises, this would definitely be a great success for the independent cultural scene. The five percent that were originally promised for 2013 will then finally be disbursed in 2015. In the long run, they are needed to implement more projects and create new jobs. 


\section{Author Biography}

The author is a professor of Public Administration at Florida International University. From 1999 to 2007 he was doing research and teaching at Leipzig University every summer. In June 2007, he was designated an Honorarprofessor of that university. He returned to Leipzig University in May 2013 for his fiftheen consecutive summers there.

\section{REFERENCES}

Cultural Department of the City of Leipzig (2008). Kulturentwicklungsplan der Stadt Leipzig für die Jahre 2008-2015.

http://www.leipzig.de/freizeit-kultur-und-tourismus/kunst-und-kultur /kulturentwicklung-und-kulturfoerderung/

Cultural Department of the City of Leipzig (2011). Kulturentwicklungsplanung. Entwicklungskonzept 2011-2015. Soziokultur. http://www.leipzig.de/freizeit-kultur-und-tourismus/kunst-und-kultur /kulturentwicklung-und-kulturfoerderung/

Department of Urban Development of the City of Leipzig (2009). Leipzig 2020. Integratives Stadtentwicklungskonzept (SEKo). http://www.leipzig.de/imperia/md/content/61_stadtplanungsamt/seko /seko_langfassung_web.pdf

Diebler, P. District manager of Leipziger Westen that includes the two major districts of Lindenau and Plagwitz. She was interviewed in July 2011 by Peter Vollmar, one of my research assistants at Leipzig University.

Reitler, T. (2012). Leipzig Plus Kultur. Abgerungener Erfolg. http://www.leipzigpluskultur.de/abgerungener-erfolg/ 